\title{
Sitting to standing postural changes: Energy expenditure and a possible mechanism to alleviate sedentary behavior
}

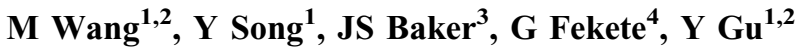 \\ ${ }^{1}$ Faculty of Sports Science, Ningbo University, Ningbo, China \\ ${ }^{2}$ Research Academy of Grand Health, Ningbo University, Ningbo, China \\ ${ }^{3}$ School of Science and Sport, University of the West of Scotland, Hamilton, UK \\ ${ }^{4}$ Faculty of Informatics, Eötvös Loránd University, Szombathely, Hungary
}

Received: July 7, 2017

Accepted: April 19, 2018

\begin{abstract}
Background and aims: Sedentary lifestyles have recently been identified as potential mechanism for obesity and associated metabolic diseases linked to ill health. The aim of this study was to investigate the effects of standing and sitting-standing positional changes on energy cost and consequently interrupting sedentary sitting time while working. Methods: A total of 26 healthy male volunteers performed normal typing and editing work for 100 min under three conditions. The conditions included sustained sitting, sustained standing, and sitting-standing alternation every 20 min using a sit-stand desk. Respiratory parameters measured included minute ventilation (VE), oxygen consumption $\left(\mathrm{VO}_{2}\right)$, and energy expenditure (EE). Measurements were recorded using a calibrated Cosmed $\mathrm{K}^{4} \mathrm{~b}^{2}$ portable gas analysis system. Results: The mean value for $\mathrm{VE}$ was the highest in the standing position ( $\mathrm{VE}=13.33 \pm$ 0.71 ), followed by sitting-standing alternation ( $\mathrm{VE}=12.04 \pm 0.62)$. Both were significantly different from sitting $(\mathrm{VE}=10.59 \pm 0.69)$. The maximum $\mathrm{VE}$ and $\mathrm{EE}$ for standing $(\mathrm{VE}=14.81 \pm 0.43$ and $\mathrm{EE}=1.84 \pm 0.10)$ and sitting-standing alternation $(\mathrm{VE}=14.80 \pm 0.40$ and $\mathrm{EE}=1.93 \pm 0.08)$ were significantly higher than that of sitting $(\mathrm{VE}=12.15 \pm 0.42$ and $\mathrm{EE}=1.67 \pm 0.07)$. No significant differences were observed in the mean $\mathrm{VO}_{2}$ among the three conditions. However, the maximum $\mathrm{VO}_{2}$ for both standing $\left(\mathrm{VO}_{2}=5.40 \pm 0.20\right)$ and sitting-standing alternation $\left(\mathrm{VO}_{2}=5.14 \pm 0.17\right)$ had shown to be significantly higher than sitting $\left(\mathrm{VO}_{2}=4.50 \pm 0.18\right)$. There were no significant differences observed in the mean $\mathrm{EE}$ levels between sitting $(\mathrm{EE}=1.43 \pm 0.07)$ and sitting-standing alternation $(E E=1.55 \pm 0.08)$. However, the mean $E E$ while standing $(E E=1.62 \pm 0.09)$ significantly increased compared to sitting. Conclusions: The findings of this study indicate that sitting-standing alternations may be implemented as an effective intervention to interrupt prolonged sitting while working.
\end{abstract}

Keywords: sedentary behavior, sitting-standing alternation, energy expenditure, health benefits, expenditure

\section{Introduction}

Sedentary behavior has long been associated with increased ill health $(11,17)$. Evidence suggests that there is a positive relationship between sitting time and risk of type II diabetes $(25,30)$ and associated pathologies $(13,23,24)$. In addition, low-energy expenditure (EE) observed during a seated posture (15) is considered to be an important contributory factor to the increased prevalence of obesity $(18,20,28)$.

Previous studies have suggested that strategies that promote activity as opposed to sedentary behavior may improve health outcomes (6). Research by Buckley et al. (2) provided guidelines for employers to promote the avoidance of prolonged periods of sedentary work,

\footnotetext{
Corresponding author: Prof. Yaodong Gu

Faculty of Sports Science, Ningbo University

No. 818 Fenghua Road, Ningbo 315211, China

Phone: +86 574 87609371; Fax:+86 574 87600456; E-mail: guyaodong@hotmail.com
} 
suggesting that seated-based work should be regularly alternated with the goal of accumulating $2 \mathrm{~h}$ of standing per day. Potential mechanism for promoting health by reducing sedentary time may be associated with increased oxidative metabolism when using treadmill and sit-stand workstations during walking and standing. In a work-based environment, EE while sitting is reported to be $45-76 \mathrm{kcal} / \mathrm{h}$, which increases to $88 \mathrm{kcal} / \mathrm{h}$ while standing and $148-191 \mathrm{kcal} / \mathrm{h}$ while walking $(1,9,20)$. More recently, Carter et al. (5) reported that treadmill walking led to a higher total energy consumption and heart rate compared to sitting and standing. However, the relatively high cost of a treadmill desk and related equipment is likely to limit practical applications (4). In addition, high-intensity activity (moderate-to-vigorous intensity) such as jogging on a treadmill may potentially impair work productivity and could be dangerous (21). Also, both methods would seem to be impractical in a workplace environment.

Alternatively, standing has been considered as an effective intervention used to avoid the negative effects of sedentary time without affecting work productivity (7). Buckley et al. (3) noted that along with attenuated postprandial blood glucose, EE during an afternoon standing session while working was $0.83 \mathrm{kcal} / \mathrm{min}$ higher than performing the same task while sitting. However, previous research has demonstrated that prolonged standing may lead to lower leg swelling, knee discomfort, and venous pooling (8). Lower back fatigue and pain have also been frequently reported as a consequence of prolonged standing $(14,22)$. Júdice et al. (19) compared the metabolic/energy cost between sitting, standing, and sitting-standing transition. They observed that sitting-standing transition (1 set/min) and sustained standing had a metabolic cost of $0.32 \mathrm{kcal} / \mathrm{min}$ and $0.07 \mathrm{kcal} / \mathrm{min}$ higher than sitting, respectively. However, a limitation of the study was that it measured metabolic cost only for a short time period (10 min).

Because it is not feasible to repeat one set of sitting-standing transition per minute during an 8-h work period, the effects of longer durations of standing or sitting-standing alternations on energy cost in attenuating sedentary behavior remain unclear. Therefore, the purpose of this study was to explore the respiratory differences in minute ventilation (VE), relative oxygen consumption $\left(\mathrm{VO}_{2}\right), \mathrm{EE}$, and respiratory exchange ratio (RER) between sitting, standing, and sitting-standing postural changes every 20 min during $100 \mathrm{~min}$ of actual working time. It was hypothesized that standing and sitting-standing alternation would increase energy cost compared with sustained sitting.

\section{Materials and Methods}

\section{Study design}

A total of 26 healthy males volunteered to participate in this experiment. The average age of participants was $23.20 \pm 1.83$ years, the average stature was $177.65 \pm 4.47 \mathrm{~cm}$, the average mass was $69.5 \pm 3.68 \mathrm{~kg}$, and the average body mass index (BMI) was $21.99 \pm 0.89 \mathrm{~kg} / \mathrm{m}^{2}$. Participants with smoking history, cardiovascular disease, and endocrine and metabolic disorders were excluded from the study following medical screening. This study was approved by the Human Ethics Committee of Ningbo University (Reference number: ARGH20160621). All subjects were informed about the consent for inclusion in the study, the goal, and funding organization of the study.

\section{Equipment}

A calibrated $\mathrm{K}_{4} \mathrm{~b}^{2}$ portable gas analysis system (COSMED, Rome, Italy) was used to measure respiratory parameters. The $\mathrm{K}_{4} \mathrm{~b}^{2}$ system has been proven as a valid and reliable device for measuring $\mathrm{VO}_{2}(10)$. It is a portable telemetric analysis system measuring $\mathrm{VE}$, 
$\mathrm{F}_{\mathrm{E}} \mathrm{O}_{2}$ (fractional concentrations of expired oxygen), $\mathrm{F}_{\mathrm{E}} \mathrm{CO}_{2}$ (carbon dioxide), $\mathrm{VO}_{2}$, and $\mathrm{VCO}_{2}$ (the volume of carbon dioxide produced) during breathing. Prior to data collection, the system was calibrated using the unit's microprocessor in conjunction with the Haldane transformation algorithm. A sit-stand desk (Loctek, China), the height of which was adjusted to the height of participants using an electric system, was used in the experiment.

\section{Study design and data collection}

Environmental temperature in the laboratory was kept controlled and constant between 21 and $24{ }^{\circ} \mathrm{C}$. Participants were required to avoid strenuous exercise $24 \mathrm{~h}$ prior to testing. The participants were also told to avoid using caffeine or other stimulants $24 \mathrm{~h}$ prior to the test and to avoid food consumption $2 \mathrm{~h}$ before the commencement of the experiment. Each subject was advised to adjust the desk height while sitting as well as standing. This facilitated a comfortable and erect posture under all conditions. Additionally, all subjects were given familiarization periods to ensure that they could work comfortably wearing the $\mathrm{K} 4 \mathrm{~b}^{2}$ portable gas analysis system face mask. For each subject, tests were implemented under three conditions within 3 days. During measurement, all subjects were required to perform normal text-editing tasks or video-watching activities lasting $100 \mathrm{~min}$ at the same time period of each day. This avoided the effects of diurnal variation on data collection between the three conditions. Subjects were randomly assigned to each condition. Talking was not allowed during the data collection period. The different testing conditions are outlined below:

Condition 1 (Day 1): On the first day, tests were performed under sitting conditions from 9:30 to $11: 10$ a.m. The average height of desk was $86 \pm 4.92 \mathrm{~cm}$.

Condition 2 (Day 2): On the second day, tests were performed under standing conditions from 9:30 to 11:10 a.m. The average height of the desk was $115 \pm 5.01 \mathrm{~cm}$.

Condition 3 (Day 3): On the third day, tests were performed under sitting-standing conditions from 9:30 to 11:10 a.m. Posture alteration occurred every $20 \mathrm{~min}$ with a starting posture of standing (session 1 - standing from 9:30 to 9:50 a.m.; session 2 - sitting from 9:50 to 10:10 a.m.; session 3 - standing from 10:10 to 10:30 a.m.; session 4 - sitting from 10:30 to $10: 50$ a.m.; and session 5 - standing from 10:50 to 11:10 a.m.). The average height of desk while standing and sitting was $115 \pm 5.01$ and $86 \pm 4.92 \mathrm{~cm}$, respectively.

\section{Statistical analysis}

Respiratory parameters for $\mathrm{VE}, \mathrm{VO}_{2}, \mathrm{EE}$, and RER during the 100-min test were collected and selected for analysis. Descriptive subject characteristics were presented as mean \pm SD. All analyses were conducted using SPSS for Windows, version 19.0 (SPSS Inc., Chicago, IL, USA). An analysis of variance was used to examine differences in $\mathrm{VE}, \mathrm{VO}_{2}$, and EE between the different postures of standing, sitting, and sitting-standing. Significance level was set at $P<0.05$. The Bonferroni post-hoc test was conducted where significant differences were observed.

\section{Results}

Figure 1 shows values for $\mathrm{VO}_{2}, \mathrm{VE}$, and EE between sitting, standing, and sitting-standing during 100-min testing. Although the mean $\mathrm{VO}_{2}$ for standing and sitting-standing alternation was $16.83 \%$ and $14.36 \%$ higher than sitting, respectively, there were no significant differences among the three conditions (Table I). The maximum $\mathrm{VO}_{2}$ for both standing 


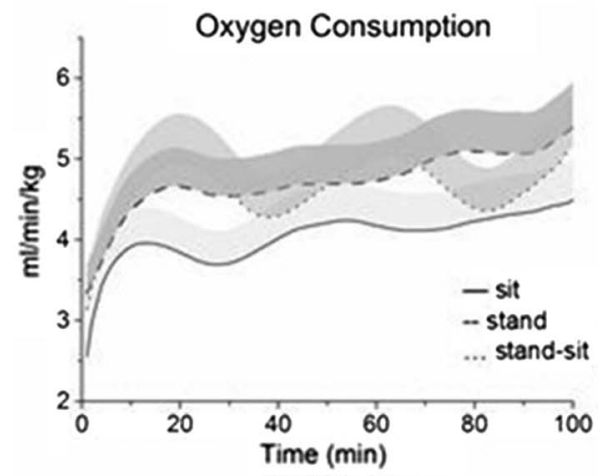

(a)

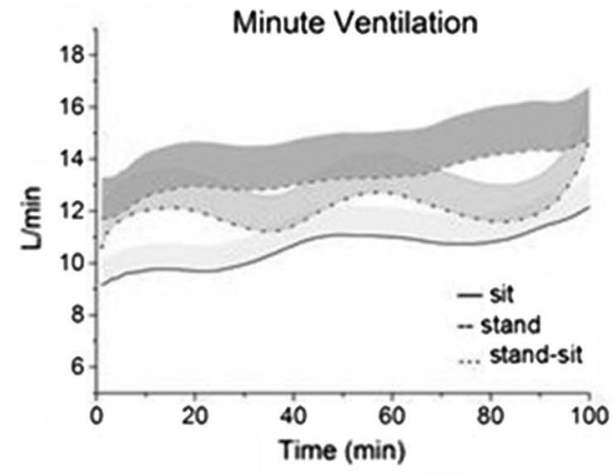

(b)

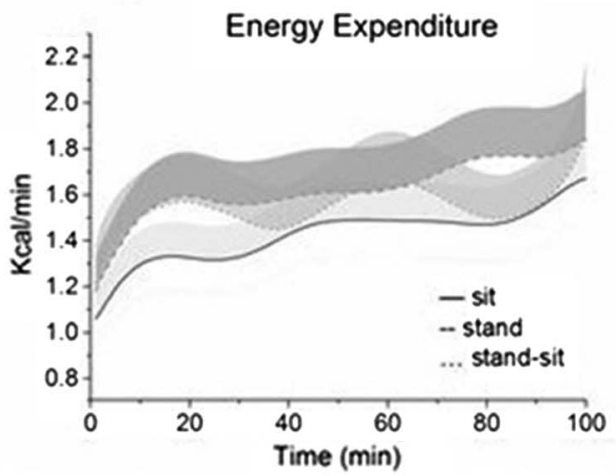

(c)

Fig. 1. Comparison of oxygen consumption $\left(\mathrm{VO}_{2} ; \mathrm{a}\right)$, minute ventilation (VE; b), and energy expenditure (EE; c) between sitting (solid line), standing (dashed line), and sitting-standing alternation (dotted line) during 100-min test

and sitting-standing alternation had shown to be significantly higher than sitting (Table I). As shown in Fig. 1a, the curve for $\mathrm{VO}_{2}$ exhibits a rapid increase in the first 10 min for sitting and 20 min for standing and sitting-standing posture change. The curve for $\mathrm{VO}_{2}$ in the standing condition enters into a relatively steady phase with a slight increase. During sitting, it shows a second peak approximately at the 50-min testing stage. Differing from the curve recorded for sitting and standing, the curve for sitting-standing posture alternation seems to be more irregular and fluctuating.

As shown in Fig. 1b, the mean VE for standing is the highest during the entire 100-min testing period, followed by the sitting-standing postural change with sitting recording the lowest value. The curves of VE of standing and sitting show a constant trend compared with sitting-standing postural change. Similar to the curve observed for $\mathrm{VO}_{2}$, the curve for VE recorded for sitting-standing postural change also seems to be irregular and fluctuating. Changes for mean EE are comparable with VE corresponding to each condition (Fig. 1c). The maximum $\mathrm{VE}$ and $\mathrm{EE}$ for standing and sitting-standing alternation were significantly higher than that of sitting (Table I). Significant difference was also observed in the mean EE between sitting and standing (Table I). The differences were not significant when comparisons were made between sitting and sitting-standing postural changes (Table I). 
Table I. Characteristics of $\mathrm{VO}_{2}$, VE, EE, and RER during 100-min sitting (sit); standing (stand), and sitting-standing alternation (sit-stand) (mean $\pm \mathrm{SD})$

\begin{tabular}{|l|c|c|c|c|}
\hline \multicolumn{2}{|c|}{} & Sit & Stand & Sit-stand \\
\hline \multirow{2}{*}{$\mathrm{VO}_{2}(\mathrm{ml} / \mathrm{min} / \mathrm{kg})$} & Mean & $4.04 \pm 0.38$ & $4.72 \pm 0.42$ & $4.62 \pm 0.49$ \\
\cline { 2 - 5 } & Increase \% & - & $16.83 \pm 3.46$ & $14.36 \pm 2.72$ \\
\cline { 2 - 5 } & Max & $4.50 \pm 0.18$ & $5.40 \pm 0.20^{* *}$ & $5.14 \pm 0.17^{\#}$ \\
\hline \multirow{2}{*}{$\mathrm{VE}\left(\mathrm{min}^{-1}\right)$} & Mean & $10.59 \pm 0.69$ & $13.33 \pm 0.71^{* *}$ & $12.04 \pm 0.62^{\#}$ \\
\cline { 2 - 5 } & Increase \% & - & $25.87 \pm 5.83$ & $13.69 \pm 2.02$ \\
\cline { 2 - 5 } & Max & $12.15 \pm 0.42$ & $14.81 \pm 0.43^{* *}$ & $14.80 \pm 0.40^{\# \#}$ \\
\hline \multirow{2}{*}{$\mathrm{EE}(\mathrm{kcal} / \mathrm{min})$} & Mean & $1.43 \pm 0.07$ & $1.62 \pm 0.09 *$ & $1.55 \pm 0.08$ \\
\cline { 2 - 5 } & Increase \% & - & $13.28 \pm 1.88$ & $8.39 \pm 0.94$ \\
\cline { 2 - 5 } & Max & $1.67 \pm 0.07$ & $1.84 \pm 0.10^{* *}$ & $1.93 \pm 0.08^{\#}$ \\
\hline \multirow{2}{*}{$\mathrm{RER}$} & Mean & $0.83 \pm 0.08$ & $0.85 \pm 0.09$ & $0.87 \pm 0.05$ \\
\hline
\end{tabular}

Increase \% refers to percentage increases of the mean $\mathrm{VO}_{2}, \mathrm{VE}$, and EE while standing and sitting-standing alternation compared with sitting. "-" refers to none value. $\mathrm{VO}_{2}$ : oxygen consumption; VE: minute ventilation; EE: energy expenditure; RER: respiratory exchange ratio.

$* P<0.05$, sit versus stand.

${ }^{\#} P<0.05$, sit versus stand-sit.

$* * P<0.01$, sit versus stand.

${ }^{\# \#} P<0.01$, sit versus stand-sit

Figure 2 shows the segmented EE every 20 min. As listed in Table II, the total EE for standing was higher than sitting, and statistical analysis showed significant differences during all segmented periods. Differences in the total EE between sitting-standing postural change and sitting was not noticeable compared to sitting, except for the first period (from 0 to $20 \mathrm{~min})(P<0.041)$. Results of the mean EE per minute remained consistent with the total EE. With regard to the increase rate of EE per minute, it showed negative values during sitting periods of sitting-standing postural changes (the second and fourth periods) with downward trend. EE also showed a raising/upward trend during standing periods (the first, third, and fifth periods; Fig. 2).

\section{Discussion}

Office workers spend hours sitting at desks without ambulation; as a result, intermittent standing during office work provides a simple and feasible intervention to reduce the negative effects of sedentary time by increasing EE. This study provided evidence how sittingstanding postural changes affect sedentary behavior in terms of energy cost.

Different from moderate exercise of sitting-standing transition with a frequency of one repetition per minute reported by Júdice et al. (19), this study tested energy cost under minimal intensity physical activity of sitting-standing alternation every $20 \mathrm{~min}$. Additionally, longer duration of 100 -min testing is more realistic for simulating sedentary behavior than shorter period of $10 \mathrm{~min}$ (19). The mean VE while standing and performing sitting-standing 


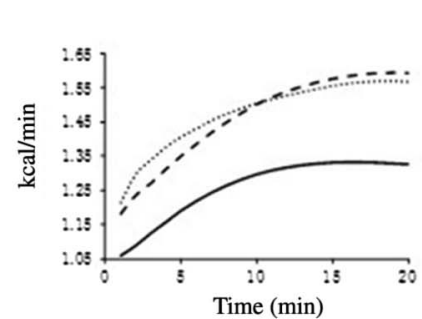

(a)

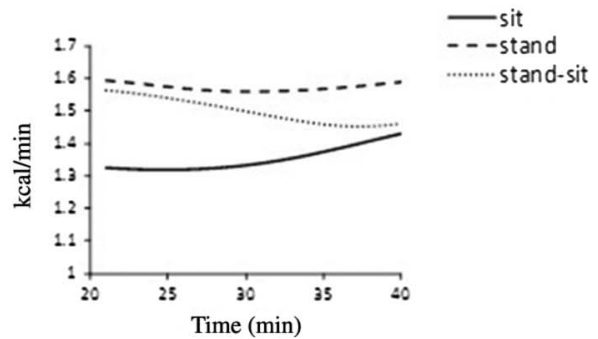

(b)

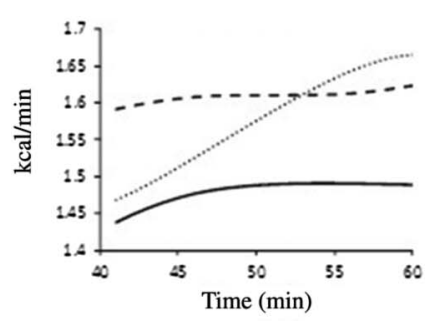

(c)

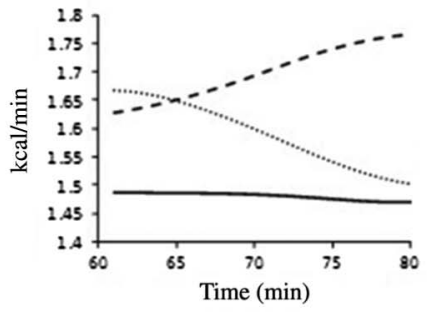

(d)

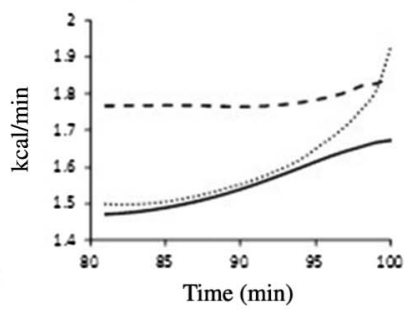

(e)

Fig. 2. Segmented energy expenditure. From 0 to $20 \mathrm{~min}$ (a), 20 to $40 \mathrm{~min}$ (b), 40 to $60 \mathrm{~min}$ (c), 60 to $80 \mathrm{~min}$ (d), and 80 to $100 \mathrm{~min}$ (e) while sitting (solid line), standing (dashed line), and sitting-standing alternation (dotted line)

alternation increased significantly $(P<0.05)$ compared with sitting. In contrast to expected outcomes, statistical significance in the mean EE was only observed between sitting and standing, while there were no differences observed between the sitting and sitting-standing condition. Thorp et al. (27) investigated EE while sitting and alternating between standing and seated work posture for every $30 \mathrm{~min}$ among a group of obese individuals. Findings from the study indicated that intermittent standing at work can modestly increase (13\%) daily workplace EE compared with seated work. Moreover, it is important to highlight that if the standing portion of the sit-stand cycle is too long, it may lead to musculoskeletal discomfort, swelling and fatigue in lower limbs, low back pain, and chronic venous insufficiency $(8,26)$. Research by Hasegawa et al. (16) supported the notion that change of posture while sitting helps to alleviate the feeling of fatigue during short-term light repetitive tasks. There was a gradual decline in EE during the second and fourth periods in the sitting-standing alternating condition. In contrast, the curves generated for the sitting and standing condition appear to be flat with an obvious increase noted during the fourth period. It is feasible to suggest that sitting periods while sitting-standing alternation could be classified as recovery phases, which may help to reduce any fatigue caused by prolonged periods of standing. With respect to work productivity, Ebara et al. (12) stated that there was a tendency to be more productive when a combination of 10-min sitting and 5-min standing compared with sustained sitting within 150 min was investigated. In spite of the decline in EE during the second and fourth periods in this study, the mean EE of sitting-standing alternation was $8.39 \%$ higher than sitting during the entire 100-min testing period. It seems feasible that sitting-standing alternation with minimal intensity may lower the health risks associated with sedentary behavior without affecting productivity in the work place.

It is also possible to suggest that the responses observed by influencing sedentary time of 100-min durations with standing and sitting-standing alternations for every 20 min have the 
Table II. Comparison of energy expenditure during different phases

\begin{tabular}{|c|c|c|c|c|}
\hline Phases & & Sit & Stand & Sit-stand \\
\hline \multirow[t]{3}{*}{$0-20 \mathrm{~min}$} & $V(\mathrm{kcal} / \mathrm{min})$ & $(13.26 \pm 1.49) 10^{-3 *}$ & $(20.67 \pm 3.01) 10^{-3 *}$ & $(17.5 \pm 1.86) 10^{-3 *}$ \\
\hline & Mean (kcal/min) & $1.260 \pm 0.089$ & $1.464 \pm 0.133 *$ & $1.467 \pm 0.101^{\#}$ \\
\hline & Total (kcal) & $25.191 \pm 2.37$ & $29.292 \pm 2.61^{*}$ & $29.523 \pm 2.44^{\#}$ \\
\hline \multirow[t]{3}{*}{$20-40 \mathrm{~min}$} & $V(\mathrm{kcal} / \mathrm{min})$ & $(5.28 \pm 0.76) 10^{-3 *}$ & $(-0.22 \pm 0.06) 10^{-3 *}$ & $(-5.26 \pm 0.69) 10^{-3 *}$ \\
\hline & Mean (kcal/min) & $1.350 \pm 0.037$ & $1.570 \pm 0.011^{*}$ & $1.499 \pm 0.041$ \\
\hline & Total (kcal) & $27.007 \pm 2.19$ & $31.405 \pm 2.51 *$ & $29.971 \pm 2.22$ \\
\hline \multirow[t]{3}{*}{$40-60 \mathrm{~min}$} & $V(\mathrm{kcal} / \mathrm{min})$ & $(2.45 \pm 0.31) 10^{-3 *}$ & $(1.59 \pm 0.27) 10^{-3 *}$ & $(9.89 \pm 0.92) 10^{-3 *}$ \\
\hline & Mean (kcal/min) & $1.479 \pm 0.015$ & $1.609 \pm 0.007^{*}$ & $1.577 \pm 0.066$ \\
\hline & Total (kcal) & $29.589 \pm 2.10$ & $32.181 \pm 2.81 *$ & $31.537 \pm 2.38$ \\
\hline \multirow[t]{3}{*}{$60-80 \mathrm{~min}$} & $V(\mathrm{kcal} / \mathrm{min})$ & $(-0.88 \pm 0.01) 10^{-3} *$ & $(6.97 \pm 0.85) 10^{-3 *}$ & $(-8.23 \pm 0.9) 10^{-3 *}$ \\
\hline & Mean (kcal/min) & $1.481 \pm 0.006$ & $1.699 \pm 0.048^{*}$ & $1.589 \pm 0.058$ \\
\hline & Total (kcal) & $29.614 \pm 2.42$ & $33.975 \pm 3.15^{*}$ & $31.771 \pm 2.75$ \\
\hline \multirow[t]{3}{*}{$80-100 \mathrm{~min}$} & $V(\mathrm{kcal} / \mathrm{min})$ & $(10.01 \pm 1.58) 10^{-3 *}$ & $(3.73 \pm 0.30) 10^{-3 *}$ & $(21.7 \pm 2.65) 10^{-3 *}$ \\
\hline & Mean (kcal/min) & $1.558 \pm 0.070$ & $1.782 \pm 0.023 *$ & $1.603 \pm 0.121$ \\
\hline & Total (kcal) & $31.160 \pm 2.55$ & $35.639 \pm 3.08^{*}$ & $32.056 \pm 2.75$ \\
\hline
\end{tabular}

$V(\mathrm{kcal} / \mathrm{min})$ indicates the increase of energy expenditure per minute.

$* P<0.05$, sit versus stand.

${ }^{\#} P<0.05$, sit versus stand-sit

potential to produce longer term health benefits if the routines were performed over an extended period. Over an 8-h working day, additional EE values of 95.67 and $59.02 \mathrm{kcal}$ would be expended when performing sustained standing and sitting-standing alternations, respectively, compared with only sitting for the same period. However, previous research has suggested that prolonged standing of less than $1 \mathrm{~h}$ and a total duration of less than $4 \mathrm{~h}$ per day is considered to be safe and practical (29).

There are several limitations of this study. First, it is difficult to include all related factors, such as work stress, meetings, and associated work like duties undertaken in a real work environment. Second, this study only recruited male subjects who were under 25 years old; therefore, potential gender and age differences may contribute to the measurements observed in this study. Further research is needed to explore the contribution of these variables in the assessment of EE in the workplace.

Third, in addition to the measurement of EE, further studies could focus on physiological indices, such as blood pressure, BMI, waist circumference, blood biochemistry including cholesterol, and postprandial glucose responses. These further measures would provide potential underlying causality details between improving health outcomes and interrupting sedentary time with the intervention of sitting-standing alternations. 


\section{Conclusions}

This study confirmed that light-intensity physical activities of sustained standing and sittingstanding alternations increase the energy cost compared with sustained sitting. There were no significant differences in the mean $\mathrm{VO}_{2}$ among the three conditions. The mean VE was the highest while standing, followed by the sitting-standing alternation. The mean EE while standing was significantly higher than during sitting. In addition, it was $8.39 \%$ higher in the sitting-standing alternation condition than during sitting, but without significance. This indicates that by moderately extending the standing portion of the sitting-standing condition would result in increasing EE compared with sustained sitting alone. However, when consideration is given to the hazards associated with prolonged standing, although it is beneficial in increasing EE, it is suggested that periods of standing should be interspersed with periods of sitting to reduce fatigue.

\section{Acknowledgements}

This study was sponsored by National Natural Science Foundation of China (81772423), K. C. Wong Magna Fund in Ningbo University, National Social Science Foundation of China (16BTY085), and Loctek Ergonomic Technology Corp.

\section{Conflict of interest}

The authors declare that they have no competing interests.

\section{REFERENCES}

1. Beers EA, Roemmich JN, Epstein LH, Horvath PJ: Increasing passive energy expenditure during clerical work. Eur. J. Appl. Physiol. 103, 353-360 (2008)

2. Buckley JP, Hedge A, Yates T, Copeland RJ, Loosemore M, Hamer M, Bradley G, Dunstan DW: The sedentary office: a growing case for change towards better health and productivity. Expert statement commissioned by Public Health England and the Active Working Community Interest Company. Br. J. Sports Med. 49, 1357-1362 (2015)

3. Buckley JP, Mellor DD, Morris M, Joseph F: Standing-based office work shows encouraging signs of attenuating post-prandial glycaemic excursion. Occup. Environ. Med. 71, 109-111 (2013)

4. Carr LJ, Walaska KA, Marcus BH: Feasibility of a portable pedal exercise machine for reducing sedentary time in the workplace. Br. J. Sports Med. 46, 430-435 (2012)

5. Carter SE, Jones M, Gladwell VF: Energy expenditure and heart rate response to breaking up sedentary time with three different physical activity interventions. Nutr. Metab. Cardiovasc. Dis. 25, 503-509 (2015)

6. Chae D, Kim S, Park Y, Hwang Y: The effects of an academic-workplace partnership intervention to promote physical activity in sedentary office workers. Workplace Health Saf. 63, 259-266 (2015)

7. Chaua JY, Sukala W, Fedel K, Doc A, Engelen L, Kingham M, Sainsbury A, Bauman AE: More standing and just as productive: effects of a sit-stand desk intervention on call center workers' sitting, standing, and productivity at work in the Opt to Stand pilot study. Prev. Med. Rep. 3, 68-74 (2016)

8. Chester MR, Rys MJ, Konz SA: Leg swelling, comfort and fatigue when sitting, standing, and sit/standing. Int. J. Ind. Ergon. 29, 289-296 (2002)

9. Cox RH, Guth J, Siekemeyer L, Kellems B, Brehm SB, Ohlinger CM: Metabolic cost and speech quality while using an active workstation. J. Phys. Act. Health 8, 332-339 (2011)

10. Duffield R, Dawson B, Pinnington HC, Wong P: Accuracy and reliability of a Cosmed $\mathrm{K} 4 \mathrm{~b}^{2}$ portable gas analysis system. J. Sci. Med. Sport 7, 11-22 (2004)

11. Dunstan DW, Howard B, Healy GN, Owen N: Too much sitting - a health hazard. Diabetes Res. Clin. Pract. 97 , 368-376 (2012) 
12. Ebara T, Kubo T, Inoue T, Murasaki GI, Takeyama H, Sato T, Suzumura H, Niwa S, Takanishi T, Tachi N, Itani T: Effects of adjustable sit-stand VDT workstations on workers' musculoskeletal discomfort, alertness and performance. Ind. Health 46, 497-505 (2008)

13. Ekblom-Bak E, Hellénius ML, Ekblom B: Are we facing a new paradigm of inactivity physiology? Br. J. Sports Med. 44, 834-835 (2010)

14. Gallagher KM, Callaghan JP: Early static standing is associated with prolonged standing induced low back pain. Hum. Mov. Sci. 44, 111-121 (2015)

15. Hamilton MT, Hamilton DG, Zderic TW: Role of low energy expenditure and sitting in obesity, metabolic syndrome, type 2 diabetes, and cardiovascular disease. Diabetes 56, 2655-2667 (2007)

16. Hasegawa T, Inoue K, Tsutsue O, Kumashiro M: Effects of a sit-stand schedule on a light repetitive task. Int. J. Ind. Ergon. 28, 219-224 (2001)

17. Healy GN, Dunstan DW, Salmon JO, Shaw JE, Zimmet PZ, Owen N: Television time and continuous metabolic risk in physically active adults. Med. Sci. Sports Exerc. 40, 639-645 (2008)

18. John D, Thompson DL, Raynor H, Bielak K, Rider B, Bassett DR: Treadmill workstations: a worksite physical activity intervention in overweight and obese office workers. J. Phys. Act. Health 8, 1034-1043 (2011)

19. Júdice PB, Hamilton MT, Sardinha LB, Zderic TW, Silva AM: What is the metabolic and energy cost of sitting, standing and sit/stand transitions? Eur. J. Appl. Physiol. 116, 263-273 (2016)

20. Levine JA, Miller JM: The energy expenditure of using a "walk-and-work" desk for office workers with obesity. Br. J. Sports Med. 41, 558-561 (2007)

21. Liao MH, Drury CG: Posture, discomfort and performance in a VDT task. Ergonomics 43, 345-359 (2000)

22. Marshall PW, Patel H, Callaghan JP: Gluteus medius strength, endurance, and co-activation in the development of low back pain during prolonged standing. Hum. Mov. Sci. 30, 63-73 (2011)

23. Matthews CE, George SM, Moore SC, Bowles HR, Blair A, Park Y, Troiano RP, Hollenbeck A, Schatzkin A: Amount of time spent in sedentary behaviors and cause-specific mortality in US adults. Am. J. Clin. Nutr. 95, 437-445 (2012)

24. Owen N, Healy GN, Matthews CE, Dunstan DW: Too much sitting: the population-health science of sedentary behavior. Exerc. Sport Sci. Rev. 38, 105-113 (2010)

25. Proper KI, Singh AS, Van Mechelen W, Chinapaw MJ: Sedentary behaviors and health outcomes among adults: a systematic review of prospective studies. Am. J. Prev. Med. 40, 174-182 (2011)

26. Roelen CA, Schreuder KJ, Koopmans PC, Groothoff JW: Perceived job demands relate to self-reported health complaints. Occup. Med. 58, 58-63 (2008)

27. Thorp AA, Kingwell BA, English C, Hammond L, Sethi P, Owen N, Dunstan DW: Alternating sitting and standing increases the workplace energy expenditure of overweight adults. J. Phys. Act. Health 13, 24-29 (2016)

28. Wanner M, Martin BW, Autenrieth CS, Schaffner E, Meier F, Brombach C, Stolz D, Bauman A, Rochat T, Schindler C, Kriemler S, Probst-Hensch N: Associations between domains of physical activity, sitting time, and different measures of overweight and obesity. Prev. Med. Rep. 3, 177-184 (2016)

29. Waters TR, Dick RB: Evidence of health risks associated with prolonged standing at work and intervention effectiveness. Rehabil. Nurs. 40, 148-165 (2015)

30. Wilmot EG, Edwardson CL, Achana FA, Davies MJ, Gorely T, Gray LJ, Khunti K, Yates T, Biddle SJ: Sedentary time in adults and the association with diabetes, cardiovascular disease and death: systematic review and meta-analysis. Diabetologia 55, 2895-2905 (2012) 